\title{
Output Characteristics of Graphene Field Effect Transistors
}

\author{
V.N. Mishchenka \\ Belarusian State University of Informatics and Radioelectronics, \\ P. Brovka str., 6, Minsk 220013, Belarus
}

Received 08.07.2020

Accepted for publication 08.09.2020

\begin{abstract}
The use of graphene, which has high mobility of charge carriers, high thermal conductivity and a number of other positive properties, is promising for the creation of new semiconductor devices with good output characteristics. The aim was to simulate the output characteristics of field effect transistors containing graphene using the Monte-Carlo method and the Poisson equation.

Two semiconductor structures in which a single layer (or monolayer) of graphene is placed on a substrate formed from $6 \mathrm{H}-\mathrm{SiC}$ silicon carbide material are considered. The peculiarity of the first of them is that the contact areas of drain and source were completely located on the graphene layer, the length of which along the longitudinal coordinate was equal to the length of the substrate. The second structure differed in that the length of the graphene layer was shortened and the drain and source areas were partly located on the graphene layer and partly on the substrate.

The main output characteristics of field-effect transistors based on the two semiconductor structures considered were obtained by modeling. The modeling was performed using the statistical Monte Carlo method. To perform the simulation, a computational algorithm was developed and a program of numerical simulation using the Monte-Carlo method in three-dimensional space using the Poisson equation was compiled and debugged.

The results of the studies show that the development of field-effect transistors using graphene layers can improve the output characteristics - to increase the output current and transconductance, as well as the limit frequency of semiconductor structures in high frequency ranges.
\end{abstract}

Keywords: field transistors, graphene, Monte-Carlo method, output characteristics.

DOI: $10.21122 / 2220-9506-2020-11-4-298-304$

\begin{tabular}{ll}
\hline Адрес для переписки: & Address for correspondence: \\
В.Н. Мищенко & V.N. Mishchenka \\
Белорусский государственный университет информатики и & Belarusian State University of Informatics and Radioelectronics, \\
радиоэлектроники & P. Brovka str., 6, Minsk 220013, Belarus A.G. \\
П. Бровки, 6, г. Минск 220013, Беларусь & e-mail: mishchenko@bsuir.by \\
e-таil: тіshсhепkо@bsuir.by & \\
\hline Для цитирования: & For citation: \\
V.N. Mishchenka. & V.N. Mishchenka. \\
Output Characteristics of Graphene Field Effect Transistors. & Output Characteristics of Graphene Field Effect Transistors. \\
Приборы и методы измерений. & Devices and Methods of Measurements. \\
2020. - Т. 11, № 4.- С. 298-304. & 2020, vol. 11, no. 4, pp. 298-304. \\
DОI: 10.21122/2220-9506-2020-11-4-298-304 & DOI: 10.21122/2220-9506-2020-11-4-298-304 \\
\hline
\end{tabular}




\section{Выходные характеристики графеновых полевых транзисторов}

\section{В.Н. Мищенко}

Белорусский государственный университет информатики и радиоэлектроники П. Бровки, 6, г. Минск 220013, Беларусь

Поступила 08.07.2020

Принята к печати 08.09.2020

Использование графена, который обладает высокой подвижностью носителей заряда, высокой теплопроводностью и рядом других положительных свойств, является перспективным для создания новых полупроводниковых приборов с хорошими выходными характеристиками. Целью работы являлось моделирование выходных характеристик полевых транзисторов, содержащих графен, с использованием метода Монте-Карло и решения уравнения Пуассона.

Рассмотрены две конструкции полупроводниковых структур, в которых одиночный слой (или монослой) графена располагается на подложке, сформированной из материала карбид кремния типа 6H-SiC. Особенностью первой из них является то, что контактные области стока и истока полностью располагались на слое графена, длина которого вдоль продольной координаты равнялась длине подложки. Конструкция второй структуры отличалась от первой конструкции тем, что длина слоя графена была укорочена и области стока и истока частично располагались на слое графена, а частично на подложке.

Путём моделирования получены основные выходные характеристики полевых транзисторов, построенных на основе двух рассмотренных полупроводниковых структур. Моделирование выполнялось с использованием метода статистического моделирования - метода Монте-Карло. Для выполнения моделирования был разработан вычислительный алгоритм, составлена и отлажена программа численного моделирования методом Монте-Карло в трёхмерном пространстве с использованием уравнения Пуассона.

Результаты выполненных исследований показывают, что разработка полевых транзисторов с использованием слоёв графена может улучшить выходные характеристики - увеличить выходной ток и крутизну, а также повысить предельную частоту работы полупроводниковых структур в высокочастотных диапазонах.

Ключевые слова: полевые транзисторы, графен, метод Монте-Карло, выходные характеристики.

DOI: $10.21122 / 2220-9506-2020-11-4-298-304$

\begin{tabular}{ll}
\hline Адрес для переписки: & Address for correspondence: \\
В.Н. Мищенко & V.N. Mishchenka \\
Белорусский государственный университет информатики и & Belarusian State University of Informatics and Radioelectronics, \\
радиоэлектроники & P. Brovka str., 6, Minsk 220013, Belarus A.G. \\
П. Бровки, 6, г. Минск 220013, Беларусь & e-mail: mishchenko@bsuir.by \\
e-таil: mishchenko@bsuir.by & \\
\hline Для цитирования: & For citation: \\
V.N. Mishchenka. & V.N. Mishchenka. \\
Output Characteristics of Graphene Field Effect Transistors. & Output Characteristics of Graphene Field Effect Transistors. \\
Приборы и методы измерений. & Devices and Methods of Measurements. \\
2020. - Т. 11, № 4. - С. 298-304. & 2020, vol. 11, no. 4, pp. 298-304. \\
DОI: 10.21122/2220-9506-2020-11-4-298-304 & DOI: 10.21122/2220-9506-2020-11-4-298-304 \\
\hline
\end{tabular}




\section{Introduction}

The study of output characteristics for semiconductor compounds containing graphene is an urgent task related to the development of fast and powerful devices of microwave and microwave ranges. Great prospects are connected with the use of graphene in compounds with silicon carbide, boron nitride and other materials in the composition of developed new semiconductor devices [1-3]. Studies have shown that the material of silicon carbide $\mathrm{SiC}$ can be used to form a layer of graphene on its surface and the implementation of new structures of fieldeffect transistors. Detailed analysis of the output characteristics in the SiC-based devices obtained in such a way is either absent or performed using a simplified hydrodynamic model [3]. The most correct method for the analysis of physical processes in semiconductor structures is considered to be the Monte-Carlo statistical method, which allows to take into account the scattering dynamics of charge carriers in a semiconductor, to obtain their distribution dependencies for stationary and nonstationary processes and, finally, to determine the output characteristics of devices.

Based on the Monte-Carlo method of statistical modeling, the studies of output characteristics of semiconductor structures containing a single layer of graphene placed on a silicon carbide substrate were carried out. For these purposes, a computational algorithm was developed, a program of numerical simulation by the Monte-Carlo method in threedimensional space using the Poisson equation was compiled and debugged.

\section{Constructions of semiconductor structures using graphene and features of modeling their output characteristics}

Let us consider the use of a single layer (or monolayer) of graphene in a semiconductor structure that uses silicon carbide material type $6 \mathrm{H}-\mathrm{SiC}$ as a substrate. Figure 1 shows one of the possible designs for a semiconductor structure using a single layer of graphene. For all the dependencies obtained as a result of modeling, except those specified separately, the following dimensions of the structure were taken: length along the $\mathrm{x}$ coordinate $(D X$ parameter) $1.0 \cdot 10^{-6} \mathrm{~m}$, height $-0.34 \cdot 10^{-8} \mathrm{~m}(D S$ parameter, $y$ coordinate), width ( $z$ coordinate $)-8 \cdot 10^{-6} \mathrm{~m}$ (Figure 1). The values of the $D A$ (drain length) and $D B$ (source length) parameters were taken as the same and equal to $0.2 \cdot 10^{-6} \mathrm{~m}$. The gate length ( $D Z$ parameter) was also assumed to be $0.2 \cdot 10^{-6} \mathrm{~m}$. The thickness of the graphene layer was assumed to be $0.34 \cdot 10^{-9} \mathrm{~m}$. Calculations were made for the temperature value $T=300 \mathrm{~K}$.

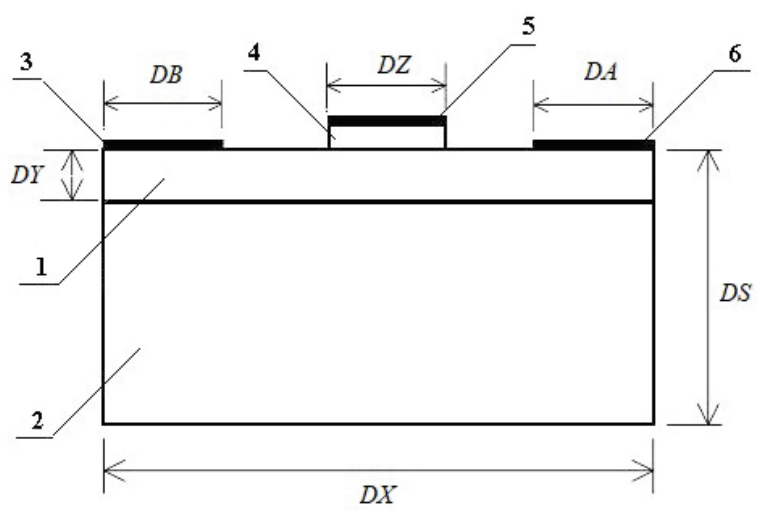

Figure 1 - Structure of a semiconductor device containing grapheme: 1 -layer of graphene; 2 -substrate made of silicon carbide material of $6 \mathrm{H}-\mathrm{SiC}$ type; 3 -source; 4 - layer of dielectric insulation material made of silicon dioxide; 5 -gate; 6 -drain

The electron drift channel was formed along the $\mathrm{x}$ coordinate by applying constant bias voltages, which were applied to the two contact areas - the drain and the gate. For $6 \mathrm{H}-\mathrm{SiC}$ material, the values of its electrophysical parameters were selected from the data presented in $[4,5]$ at a concentration of electrons equal to $1 \cdot 10^{17} \mathrm{~cm}^{-3}$. The number of simulated particles for the entire structure with a layer of graphene and a $\mathrm{SiC}$ substrate was assumed to be 10000 . Input and output of electrons from the structure according to the Monte Carlo procedure [6, 7] was carried out from the contact regions 3 of the source and 6 of the drain (Figure 1), but the regions 3 and 6 , as well as region 5 , were not considered in the modeling procedures.

The design of the transistor presented in Figure 2 is generally similar to that presented in Figure 1, but the length of the graphene layer is shortened, and the value of parameters $D K$ and $D M$ (Figure 2) is $2 \cdot 10^{-8} \mathrm{~m}$.

Thus the layer of graphene is located between contact areas of a source and a drain (elements 3 and 6 , accordingly, in Figure 1) so that these areas are partially placed on a semiconductor substrate from silicon carbide (element 2 in Figure 2), and partially on a layer of graphene (element 1 in Figure 2).

At modeling of electron transfer processes in silicon carbide material of $6 \mathrm{H}-\mathrm{SiC}$ type, the model consisting of $M_{1}-L-M_{2}$ valleys of conductivity zone 
having the lowest energy was used. The value of the gap between the $M_{1}$ and $M_{2}$ valleys was assumed to be $0.18 \mathrm{eV}[5,6]$. For the region of the structure containing graphene, the mechanisms of scattering of electrons on optical phonons, on impurities, on acoustic phonons were taken into account $[8,9]$; electron-electronic scattering was also additionally considered and its analysis is presented in [11]. In the developed program using the Monte-Carlo method for the analysis of electron drift in the region consisting of $6 \mathrm{H}-\mathrm{SiC}$ material, the scattering mechanisms on optical phonons, on impurities, on acoustic phonons, as well as the inter-valley scattering between nonequivalent valleys [10].

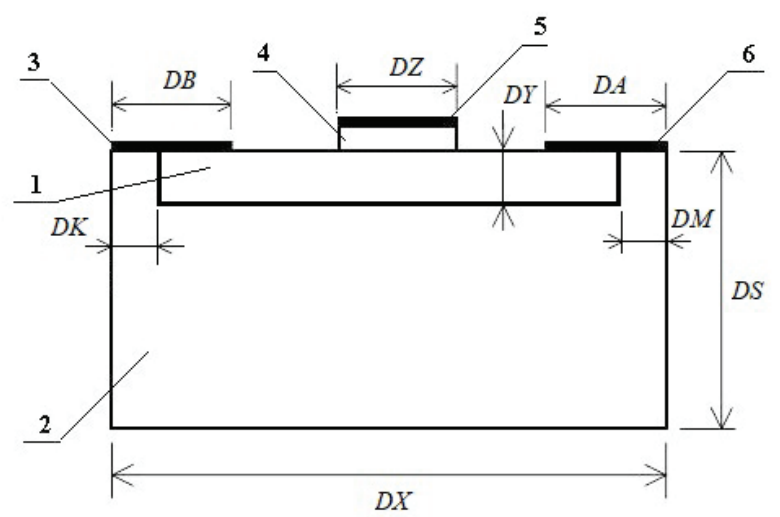

Figure 2 - Structure of a semiconductor device containing graphene: 1 -layer of graphene; 2 -substrate made of silicon carbide material of $6 \mathrm{H}-\mathrm{SiC}$ type; 3 -source; 4 - layer of dielectric insulation material made of silicon dioxide; 5 - gate; 6 -drain

To investigate the electron transfer process in graphene, the linear dependence of the energy $E$ of electrons on the wave vector $k$ was used, which is true in the region of usually considered energy values $[8,9]$ :

$$
E=\hbar \cdot v_{F} \cdot \sqrt{k_{x}^{2}+k_{y}^{2}+k_{z}^{2}},
$$

where $k_{x}, k_{y}, k_{z}$-the components of the wave vector (wave numbers) along the coordinates $x, y, z$, respectively; $v_{F}$-the Fermi speed in graphene, the value of which is usually taken as $1.0 \cdot 10^{8} \mathrm{~cm} / \mathrm{s} ; \hbar-$ reduced Planck's constant.

\section{Simulation results}

Figure 3 shows the obtained by simulation using the Monte-Carlo method and the solution of the Poisson's equation of dependence of the output current of the $I$ drain on the value of direct voltage at the gate $U_{g}$.

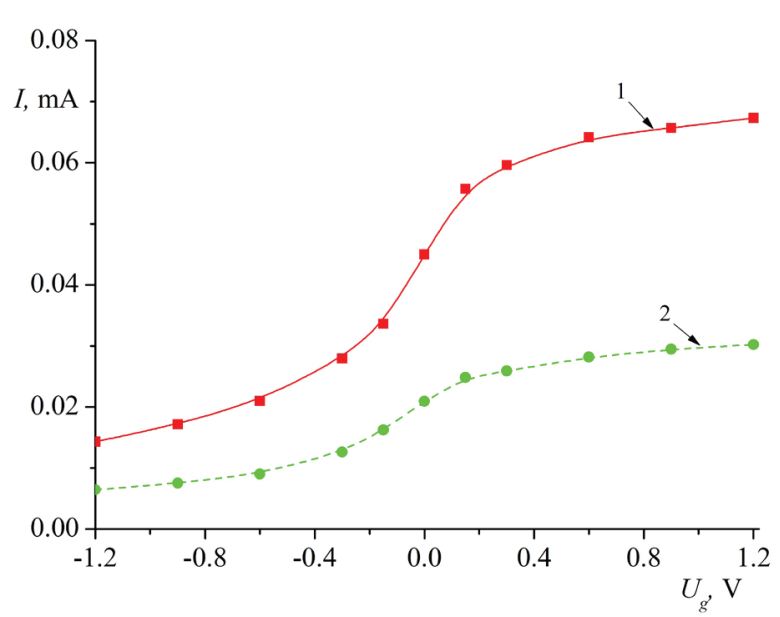

Figure 3 - Dependencies of the output drain current on the value of the constant gate voltage: 1 - obtained for the structure shown in Figure 1;2 - obtained for the structure shown in Figure 2

In this case, the value of DC voltage at the drain of $U_{\mathrm{o}}$, for all curves presented in this figure, was equal to $1.5 \mathrm{~V}$. Curve 1 was obtained for the structure shown in Figure 1, using a single layer of graphene. Curve 2 is obtained for the structure shown in Figure 2 , using a single graphene layer of the same thickness as curve 1 in this Figure.

Figure 4 shows the dependencies of drain output current $I$ and the transconductance of output characteristic $g_{m}$ on the value of constant voltage at the gate $U_{g}$ for a structure without using a single layer of graphene, while observing all other parameters, as in the structure shown in Figure 1. In doing so, the graphene layer shown in Figure 1 was replaced by a layer of silicon carbide of similar size, so that a homogeneous layer of this material is formed.

The analysis of curves 1 и 2 in Figure 3 and curve 1 in Figure 4 shows that using a layer of graphene placed between the drain and the source allows to increase the output current several times at the same size of semiconductor structures and the same values of direct voltages at the drain and the gate.

Figure 5 shows the dependencies (curves 1 and 2) of the transconductance of the output characteristic $g_{m}$ on the value of direct voltage at the gate $U_{g}$, obtained from the characteristics of the output current, presented in Figure 3 by curves 1 and 2, respectively. The analysis of these dependencies shows that the maximum transconductance of the output characteristic $g_{m}$ reaches a value of approximately $0.075 \mathrm{mS}$ at a gate voltage of approximately $0 \mathrm{~V}$ for structure 1 shown in Figure 1. 


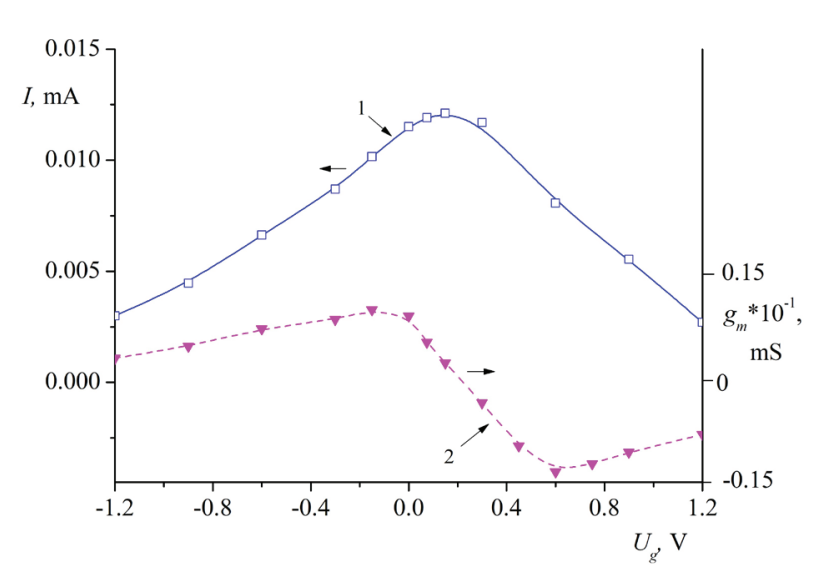

Figure 4-Dependences of output drain current and transconductance of output characteristic of the design without graphene layer on the value of constant voltage at the gate: 1 -dependence of output drain current; 2 - transconductance of output characteristic

For structure 2, shown in Figure 2, the transconductance of the output characteristic $g_{m}$ has lower values compared to structure 1 , shown in Figure 1, reaching a maximum value of approximately $0.031 \mathrm{mS}$ at a gate voltage of approximately $0 \mathrm{~V}$.

The analysis of dependencies 1 and 2 presented in Figure 5 and curve 2 in Figure 4 shows that the use of a graphene layer allows to significantly, several times increase the transconductance of the output characteristic, and thus increase the gain of the structure.

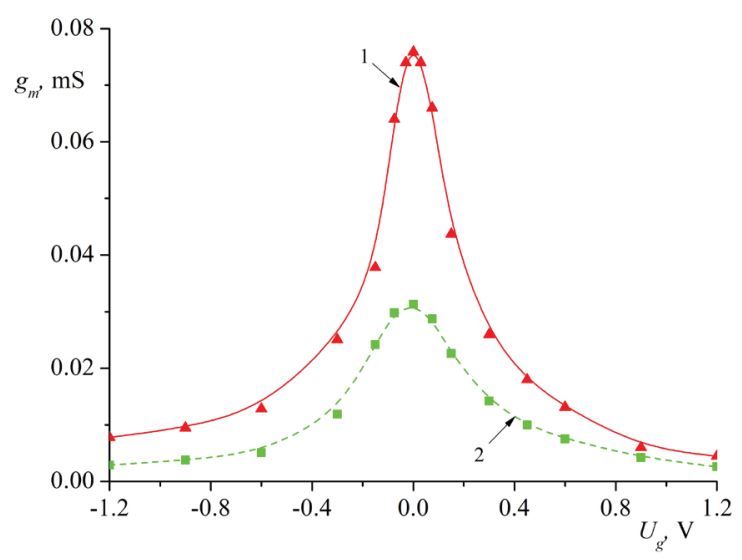

Figure 5-Dependencies of the transconductance of the output characteristic on the value of the constant gate voltage: 1 - obtained for the structure shown in Figure 1; 2 - obtained for the structure shown in Figure 2

Figure 6 shows the dependencies of the output current $I$ on the value of DC voltage $U_{0}$. The curves $1-3$ in Figure 6 are obtained at the gate voltage $U_{g}$ equal to minus $0.15 \mathrm{~V}$. Curve 1 is obtained for the design shown in Figure 1, using a single layer of graphene. Curve 2 is obtained for the structure shown in Figure 2, which is characterized by a shorter length of a layer of graphene compared with the structure shown in Figure 1. Curve 3 is obtained for the transistor structure described above, which does not contain a layer of graphene.

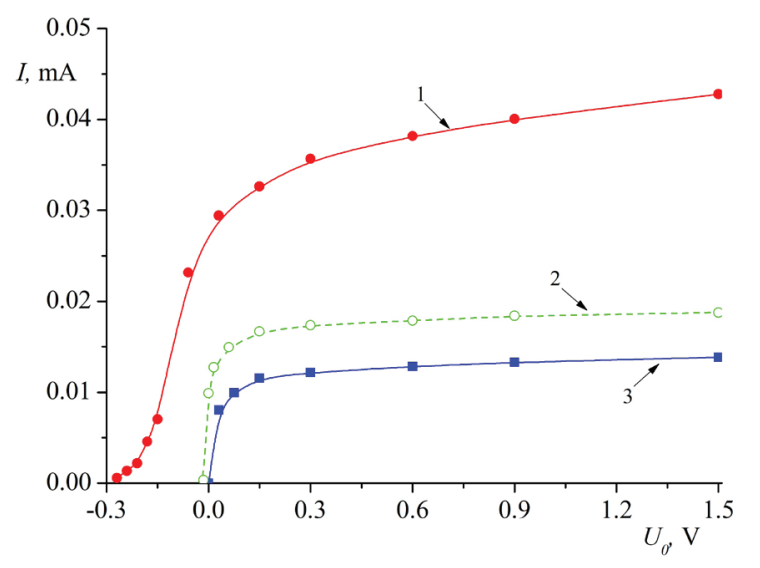

Figure 6 - Dependencies of the output drain current on the DC value of the drain voltage: 1 - obtained for the structure shown in Figure 1;2 - obtained for the structure shown in Figure 2; 3 - obtained for the structure that does not contain a layer of grapheme

The analysis of curves 1, 2 shows that the output drain current has a feature that is not observed in conventional transistor designs without using a layer of graphene, and this feature is associated with the presence of flow current, which is not equal to zero, at a voltage on the drain equal to zero. The closed state of the transistor, whose design is shown in Figure 1, is observed at a voltage on the drain, approximately equal to minus $0.29 \mathrm{~V}$, and the transistor, shown in Figure 2 at a voltage on the drain approximately -minus $0.015 \mathrm{~V}$.

The theoretical possibility of operating the semiconductor structure shown in Figure 1, which has a total length of the structure equal to $1 \cdot 10^{-6} \mathrm{~m}$ and the length of the gate equal to $0.2 \cdot 10^{-6} \mathrm{~m}$, as an amplifier for signals in the EHF range was studied. Figure 7 of curve 1 shows the output current dependence of this semiconductor structure obtained by simulation.

In this case, an external harmonic signal with a frequency of $200 \mathrm{GHz}$ and amplitude $U_{s}=0.15 \mathrm{~V}$ (curve 2 in Figure 7) was applied to the gate of the semiconductor structure at a constant voltage at the gate $U_{g}$, equal to minus $0.15 \mathrm{~V}$. Curve 3 in Figure 7 shows the dependence of output current on the time of this semiconductor structure, built using $6 \mathrm{H}-\mathrm{SiC}$ material, but without a layer of graphene. The constant voltage applied to the drain was $1.5 \mathrm{~V}$, while the gate constant voltage was minus $0.15 \mathrm{~V}$ for both calculation options. 


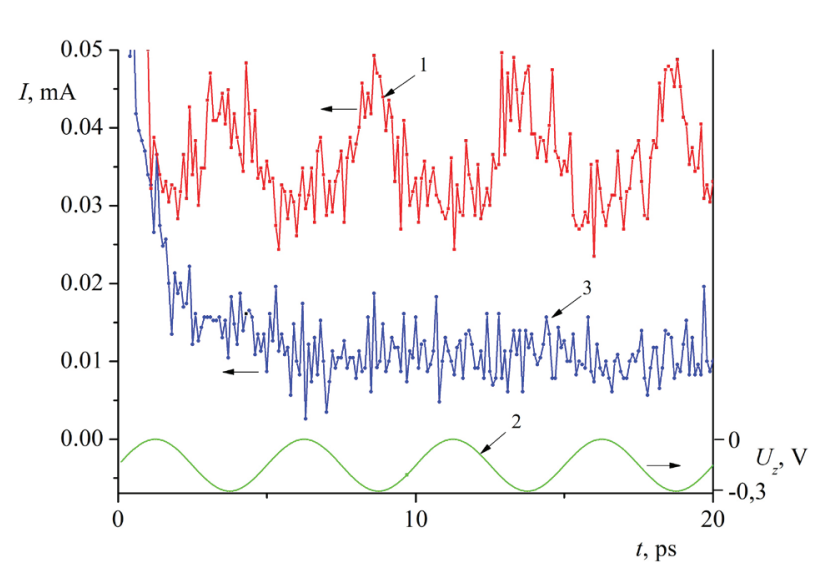

Figure 7 - Time dependencies of the output current of the semiconductor structure and the external signal applied to the gate: 1 - output current dependence of the structure shown in Figure 1;2-dependence of the external signal applied to the gate; 3 -output current dependence of the semiconductor structure constructed using $6 \mathrm{H}-\mathrm{SiC}$ material but without a graphene layer

Analysis of Figure 7 (curve 1) shows that a semiconductor structure with a layer of graphene is capable of transmitting and amplifying an input signal at $200 \mathrm{GHz}$ in the EHF range with a gate length of $1 \cdot 10^{-6} \mathrm{~m}$. A normal semiconductor structure based on silicon carbide but without graphene is unable to transmit and amplify input signals at $200 \mathrm{GHz}$ because of the low speed and mobility of charge carriers in silicon carbide (Figure 7, curve 3). Thus, the introduction of a layer of graphene into the transistor design with a silicon carbide substrate allows for a significant expansion of the frequency range of the amplifier in the EHF range.

Figure 8 shows the actual part of the complex spectrum amplitude, which was obtained by direct conversion of Fourier values of drain currents. This transformation was applied to the output current dependence data array, which is represented by curve 1 in Figure 7.

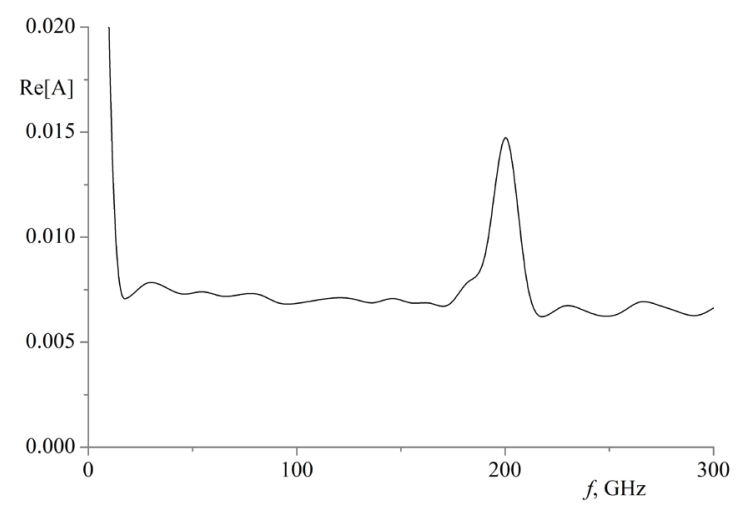

Figure 8-The real part of the complex spectrum amplitude, which was obtained by direct Fourier transformation of drain current values
The analysis of Figure 8 shows that in the received spectrum of output signal there is a component with frequency equal to $200 \mathrm{GHz}$. The analysis of Figures 7 and 8 shows that the semiconductor structure with a layer of graphene is able to transmit and amplify the input signal in the EHF range when selecting the appropriate length of the gate.

\section{Conclusion}

Modeling of output characteristics of field-effect transistors containing single graphene layer was performed using Monte-Carlo method and solution of Poisson equation. The simulation results show that the use of graphene in semiconductor compounds opens up new opportunities for improving highfrequency field-effect transistors due to high charge transfer rate, good scalability prospects, high thermal conductivity and a number of other advantages. For graphene semiconductor structures it is possible to achieve a higher average speed of electrons than in similar silicon transistors and transistors, which are based on other known semiconductor materials. Due to the use of graphene with such characteristics of charge carriers transfer it is possible to achieve high current densities in the open state and high values of transconductance, which provides good functioning characteristics and high operating frequency of field effect transistors.

The results obtained allow predicting the wide use of transistors using graphene layers for amplifiers and other devices with high output characteristics. The developed designs of graphene field-effect transistors can find wide application in radio-electronic, radar and radio-navigation systems due to expected significant improvement of output characteristics of semiconductor devices designed for operation in the microwave and microwave frequency bands.

\section{References}

1. Moon J.S., Curtis D., Bui S., Hu M., Gaskill D.K., Tedesco J.L., Asbeek P., Jernigan G.G., VanMil B.L., Myers-Ward R.L., Eddy C.R., Campbell P.M., Weng X. Top-Gated Epitaxial FETs on SiC-Face SiC Wafers with a Peak Transconductance of $600 \mathrm{mS} / \mathrm{mm}$. IEEE Electron Device Letters, 2010, vol. 31, no. 4, pp. 260-262.

DOI: $10.1109 /$ LED.2010.2040132

2. Moon J.S., Curtis D., Hu M., Wong D., McGuire C., Campbell P.M., Jernigan G.G., Tedesco J.L., VanMil B., Myers-Ward R.L., Eddy C., Gaskill D.K. 
Epitaxial-Graphene RF Field-Effect Transistors on SiFace 6H-SiC Substrates. IEEE Electron Device Letters, 2009, vol. 30, iss. 6, pp. 650-652.

3. Svintsov D.A, Vyurkov V., Lukichev V.F., Orlikovsky A.A, Burenkov A., Ohsner R. Tunnel'nye polevye tranzistory na osnove grafena. [Tunneling field effect transistors based on graphene]. Fizika $i$ tekhnika poluprovodnikov [Physics and Technology of Semiconductors], 2013, vol. 47, iss. 2, pp. 224-250.

DOI: $10.1103 /$ PhysRevB.82.115452

4. Pennington G., Goldsman N. Self-consistent calculations for n-type hexagonal $\mathrm{SiC}$ inversion layers. $J$. Appl. Phys., 2004, vol. 95, no. 8, pp. 5496-5508.

DOI: $10.1063 / 1.1687977$

5. Persson C., Lindefelt U. Dependence of energy gaps and effective masses on atomic positions in hexagonal SiC. J. Appl. Phys., 1997, vol. 86, no. 11, pp. 5036-5039. DOI: $10.1063 / 1.371475$

6. Vasileska D., Stephen M. Goodnick, Gerhard Klimeck. Computational electronics: semiclassical and quantum device modeling and simulation. CRC Press Taylor and Francis Group, 2010.

7. Damien Querlioz, Philippe Dollfus. The Wigner Monte Carlo method for nanoelectronics devices: a particle description of quantum transport and decoherence. - ISTE Ltd and JohnWiley@Sons,Inc.-2010.

8. Chauhan Jyotsna, Guo Jing. High-field transport and velocity saturation in graphene. Appl. Phys. Letters., 2009, vol. 95, p. 023120. DOI: 10.1063/1.3182740

9. Fang Tian, Konar Aniruddha, Xing Huili, Jena Debdeep. High-field transport in two-dimensional graphene. Physical Review., 2011, vol. B 84, p.125450.

DOI: $10.1103 /$ PhysRevD.84.125450

10. Murav'ev V.V., Mishchenka V.N. Modeling of electron transfer processes in a silicon carbide semiconductor structure. Doklady BGUIR, 2017, vol. 104, no. 2, pp. 53-57.

11. Murav'ev V.V., Mishchenka V.N. Simulation of the scattering rates in the monolayer graphene. Doklady BGUIR, 2017, vol. 108, no. 8, pp. 128-129. 